NBER WORKING PAPER SERIES

\title{
DEINDUSTRIALIZATION, REINDUSTRIALIZATION, AND THE REAL EXCHANGE RATE
}

Paul R. Krugman

Working Paper No. 2586

NATIONAL BUREAU OF ECONOMIC RESEARCH

1050 Massachusetts Avenue

Cambridge, MA 02138

May 1988

The research reported here is part of the NBER's research program in International studies. Any opinions expressed are those of the authors and not those of the National Bureau of Economic Research. 
NBER Working Paper \#2586

May 1988

Deindustrialization, Reindustrialization, and the Real Exchange Rate

\section{ABSTRACT}

This paper models an economy in which it is costly to move resources between the tradeable and nontradeable sectors. The economy is subject to capital flows that are unpredictable and are perceived as having only limited persistence. The model shows that both the fact that capital flows are perceived as temporary and uncertainty per se act to limit the responsivesness of resource reallocation to real exchange rate movements. In turn, this reluctance of factors to move widens the range of real exchange rate variation, so that larger movements of the real exchange rate are needed to accommodate transitory, unpredictable capital flows than would be required to accommodate persistent, predictable flows of the same magnitude. The model also shows that large capital inflows that lead to real exchange rate appreciation large enough to induce resource reallocation will typically be followed by a depreciation of the real exchange rate to below its original level.

Paul R. Krugman

NBER

1050 Massachusetts Ave.

Cambridge, MA 02138 
Changes in a country's trade balance generally involve not only substitution in demand between domestic and foreign goods, but also reallocation of resources between tradeable and nontradeable sectors. Since resource reallocation is not costless, this means that the process of adjustment to a changed capital flow involves investment decisions at the micro level -- which in turn suggests that the dynamics of trade balance adjustment will involve expectations as well as current values of economic variables, and that uncertainty will affect the pace and character of the adjustment process. The dynamics of trade balance adjustment, in turn, must have a bearing on the behavior of exchange rates. So it is important to attempt to model fust how it is that resources get reallocated when trade balances do change.

This issue has become particularly relevant now. The massive capital inflows to the US in the 1980 s had as their counterpart a considerable reallocation of resources out of US tradeable sectors, with employment and capacity falling sharply in many export and import-competing industries. This "deindustrialization" in the US had as its counterpart a corresponding growth of capacity abroad. With a decline in the willingness of foreigners to continue to supply capital to the US, there has been a sharp decline in the real exchange rate -. but a disappointingly sluggish reduction in the US trade deficit. In popular discussions of the failure of US trade to turn around more quickly, a common theme is that uncertainty has inhibited the adjustment process -. that both US and foreign firms have been reluctant to shift resources, both because they have viewed the strong dollar as 
likely to return, and because in an uncertain environment they have adopted a general "wait-and-see" attitude. There is now widespread concern that the sluggish response of trade flows to the exchange rate, brought about in part because of past exchange rate volatility, will lead to further future volatility, because the declining dollar will now have to "overshoot" its long run level in order to persuade US firms to invest in the "reindustrialization" that is now needed.

Recent theoretical work in international economics has helped to provide an analytical basis for these concerns. Baldwin and Krugman (1987) argued that fixed costs of entering and leaving markets could lead to "hysteresis" in the trade balance: an appreciation that induces US firms to exit and foreign firms to enter markets would require a subsequent depreciation below the original point to induce them to move back. Dixit $(1987 a, b)$ showed that a volatile exchange rate reinforces the "wait and see" attitude of firms that must pay a price to enter or exit markets: in effect, moving resources becomes the exercise of an option, which adds a sort of shadow fixed cost to resource reallocation. Krugman (1988) suggests that this response to uncertainty leads to a multiplier process of real exchange rate volatility: the more volatile the exchange rate; the less responsive is trade; the less responsive is trade, the more volatile the exchange rate. This rapidly emerging literature is highly suggestive of the importance of thinking about how resources get reallocated in an uncertain world.

In the theoretical literature to date, however, the problem 
of the simultaneous determination of resource reallocation and exchange rate behavior has not been formally tackled. Dixit's analysis simply posits an exchange rate process, without asking how the behavior of firms might affect this process. Baldwin and Krugman offer a preliminary analysis of joint determination, but the analysis depends on the highly unsatisfactory assumption of iid shocks to the capital account. Thus the obvlous need is for an approach that in at least a minimal way links the problem of reallocating resources to the behavior of the real exchange rate, and vice versa.

This paper offers an effort to do this. I consider a minimal model in which a country faces uncertain future capital flows and in which it is costly to move resources between the tradeable and nontradeable sectors of the economy. In this model real exchange rate behavior and the investment behavior of individual agents are jointly determined. The model is not a complete analysis of the real exchange rate problem: the process generating capital flows is simply assumed, not grounded in maximizing behavior. Nonetheless, the approach makes at least a step toward greater completeness, and yields highly suggestive results.

There are two main conclusions from the model. The first is that an economy subject to transitory, uncertain capital movements will exhibit wider fluctuations in its real exchange rate than the same economy would need to accommodate sustained, predictable capital flows of the same magnitude. The reason is the unwillingness of firms to reallocate resources in the former case: regarding the real exchange rates associated with capital 
movements as likely to be temporary, they will not shift resources even when the real exchange rate is sufficiently high or low that it would appear profitable to do so; and they will also be inhibited from moving resources by the "option" cost that results from uncertainty per se. Thus widened movements of the real exchange rate become necessary in order to accommodate any given capital movement.

The other main conclusion is that large exchange rate changes will indeed typically require subsequent "overshooting" in the opposite direction. The extent of this overshooting will be greater, the greater the inhibitory effects on reallocation described above.

The paper is in five parts. The first part sets out the basic assumptions of the model. The second part describes the analytical technique used to find equilibrium behavior. The third part explicitly derives behavior in several special cases for which closed form solutions can be derived, while the fourth part discusses the general case with the aid of numerical illustrations. A final section considers the implications of the model and possible directions for future research.

\section{Assumptions of the model}

We consider a country that consumes two goods: a nontraded good and a composite tradeable. Since this model will be concerned with dynamics and expectations, it will be necessary both to specify preferences over the two goods at each point in time and 
to specify intertemporal choices. The intertemporal choice will be the result of maximizing a utility function of the form

$$
W=\int_{0}^{\infty} U\left(C_{N}, C_{T}\right) e^{-r t} d t
$$

where $C_{N}, C_{T}$ are instantaneous rates of consumption of the two goods; $U($.$) is the instantaneous utility function; and r$ is the rate of time preference.

The function $U($.$) will be assumed to take on a very special$ form, one that will make analysis much easier, namely

$$
\mathrm{U}\left(\mathrm{C}_{\mathrm{N}}, \mathrm{C}_{\mathrm{T}}\right)=\mathrm{C}_{\mathrm{N}}+\alpha \mathrm{C}_{\mathrm{T}}-(\beta / 2) \mathrm{C}_{\mathrm{T}}^{2}
$$

The key simplifying assumption here is that utility is linear in $\mathrm{C}_{\mathrm{N}}$. Together with (1), this implies that there will be a constant real discount rate $r$ in terms of the nontraded good. It also implies that there will be no income effects in the demand for the traded good, so that a quasi-partial-equilibrium analysis becomes possible. The quadratic form of (2) is less important; it simply insures a linear demand curve for the traded good, which makes analytical solution of the model easier but does not affect the fundamental results.

The country can produce both goods. There is a single resource $R$ that can be used in either sector:

$$
R=R_{N}+R_{T}
$$


In the tradeable sector, we assume that one unit of resource produces one unit of the good. Consumption of the good is domestic production plus the trade deficit:

$$
C_{T}=R_{T}+B
$$

We want to assume that it is costly to shift resources between sectors. I will suppose that in order to move one unit of the resource either into or out of the tradeable sector requires the use of $\gamma$ units of resource in the nontradeable sector (i.e., the "resource-moving" sector - construction? - is treated as a part of the nontraded sector, not as a separate sector which itself requires costly entry and exit of resources). Thus the production of nontraded goods for consumption depends on the resources left over after allowing for any movement of resources between sectors. Again choosing units so that one unit of the resource produces one unit of the good, we have

$$
C_{N}-R_{N}-\gamma\left|\dot{R}_{T}\right|
$$

Up to this point the model is a full intertemporal optimization setup, albeit with some special assumptions. A key variable, however, is the trade deficit B. Ideally, we should model the current account as the consequence of savings and investment choices, and derive the trade account as the current account less net interest payments on past investments. For the purposes of the present model, however, this would be very 
difficult (and in any case the ability of an optimizing approach to account for exchange rate movements is highly doubtful!). Thus I take an ad hoc approach instead, one that is intended to make the linkage between real adjustment and real exchange rate behavior without getting too deeply into the determinants of the capital account. The approach is to ignore investment income, setting the trade balance equal to the negative of the capital account; and to impose directly more or less plausible but arbitrary behavior on that account ${ }^{1}$. Specifically, the trade deficit, a.k.a. the capital account, follows a stochastic process of the form

$$
d B=-\rho B d t+\sigma d z
$$

This may be interpreted as follows. Capital flows fluctuate randomly, but show a tendency to return to zero, imparting a cyclic character to the capital account. The parameter $\rho$ measures the strength of the tendency for capital flows to end (or equivalently is an inverse index of the persistence of current account imbalances). The parameter $\sigma$ is a measure of the uncertainty of future capital flows. As we will see shortly, the

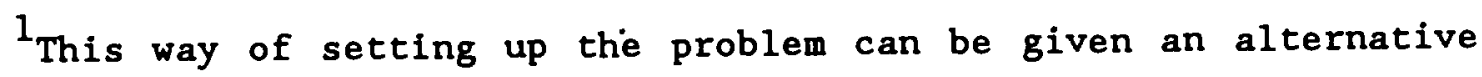
interpretation: there is no capital mobility, and $B$ is a random transfer payment from abroad. In a formal sense this is the correct description of the model; but I want to think of the model as yielding insights about behavior under mobile if perhaps erratic capital as well. 
larger are both $\rho$ and $\sigma$, the more reluctant economic agents will be to reallocate resources to the sector in which they earn the higher return.

We have now laid out the basic assumptions of the model. The next step is to formulate the optimal resource allocation problem.

\section{Determinants of resource allocation}

For any given allocation of $R$ between the tradeable and nontradeable sectors, and for any given rate of capital inflow $B$, it is straightforward to determine the relative price of tradeable goods that clears the market. We have

$$
e=\alpha-\beta\left(R_{T}+B\right)
$$

where $e$ is the price of traded relative to nontraded goods, and will be referred to as the real exchange rate (recognizing that this is one of a number of possible definitions).

Given the simple production structure of this model, the real exchange rate is immediately a measure of the relative earnings of the resource in te two sectors. One unit of resource always earns one unit of nontradeable per period in the nontradeable sector; it earns $e$ units in the tradeable sector. If resources could be costlessly moved between sectors, e would always equal one.

Since resources cannot be moved costlessly, e will in general not equal one. Resources will only be moved when moving a unit of resource from one sector to the other increases its value by as 
much as the cost of moving. Thus the main concern of the analysis must be with the valuation of a unit of resources in place in either sector - or more particularly, with the difference in value of a unit in resource in the traded as opposed to the nontraded sector.

The key variable is the increase in value that would occur if a unit of resources were moved from the nontraded to traded sector. This variable may of course take on negative values, corresponding to the case where the resource would be worth more in the nontraded sector. Let us denote this value as $V\left(R_{T}, B\right)$; it is clearly a function of these two variables, which summarize completely the state of the economy at any point in time.

$V\left(R_{T}, B\right)$ may be thought of as the value of a kind of asset, where the asset is the state of having a unit of resources in the traded rather than the nontraded sector. (The "asset" can take on negative values, but this poses no problems). The return on this asset has two parts: the "earnings", measured by the difference between what the resource earns in tradeables and what it could earn in nontradeables, and the "capital gains", the expected rate of increase of the asset's value. Together these returns must add to an overall rate of return $r$. Thus we have the condition

$$
r V\left(R_{T}, B\right)=(e-1)+E\left[d V\left(R_{T}, B\right) / d t\right]
$$

which may be rearranged to yield the asset-pricing equation

$$
V\left(R_{T}, B\right)=r^{-1}(e-1)+r^{-1} E\left[d V\left(R_{T}, B\right) / d t\right]
$$


The role of expectations appears in the form of the expected change in valuation. For a given $R_{T}$, the expected change in $V$, using the usual rules of stochastic calculus, is

$$
\mathrm{E}\left[\mathrm{dV}\left(\mathrm{R}_{\mathrm{T}}, \mathrm{B}\right) / \mathrm{dt}\right]=-\rho \mathrm{BV} \mathrm{B}_{\mathrm{B}}+\left(\sigma^{2} / 2\right) \mathrm{V}_{\mathrm{BB}}
$$

What about changes in $R_{T}$ ? As long as $-\gamma<V<\gamma$, there is no incentive to move resources between sectors. When $V$ would otherwise exceed $\gamma$, resources will move into the tradeable sector so as to keep $V=\gamma$. When $V$ would otherwise be less than $-\gamma$, resources will move out of the traded sector so as to keep $V=-\gamma$. The analysis of the model, then, requires finding for each value of $R_{T}$ the function $V\left(R_{T}, B\right)$ that satisfies (9) and also is consistent with the fact that resources will be reallocated when $V$ reaches its upper or lower limit.

\section{Three special cases}

We can derive explicit expressions for $V($.$) , and thus$ describe real exchange rate behavior, in three special cases. While these cases are problematic, they help to suggest the final form of the answer.

Static expectations

The first and simplest case is where $\rho-0$ and $\sigma^{2}-0$. That is, 
there is no tendency for capital flows to end and no uncertainty. This case is problematic, in the sense that if it were literally true the capital flow would never change; however, it may be interpreted as the case where capital flows are permanent and predictable enough that firms have essentially static expectations.

In this case $E[d V / d t]$ is zero; so the value function takes the simple form

$$
\mathrm{V}\left(\mathrm{R}_{\mathrm{T}}, \mathrm{B}\right)=\mathrm{r}^{-1}\left[\alpha-\beta\left(\mathrm{R}_{\mathrm{T}}+\mathrm{B}\right)-1\right]
$$

The implications of (10) are shown in Figure 1. For each allocation of resources there is a downward sloping $V$ function in B,V space. That is, the higher the capital inflow, the lower the value of having resources in the traded goods sector. The higher the value of $R_{T}$, the further to the left this line lies. That is, when more resources are committed to the traded goods sector, the capital inflow must be smaller or the capital outflow larger in order to make the value of keeping them in that sector as great as before. By bearing in mind that $R_{T}$ shifts when $V$ hits its upper or lower bound, and that when it does the economy moves onto a new V-schedule, we can use Figure 1 to represent the movements of three variables in two dimensions.

The dynamics of resource reallocation in this special case may be best understood by considering a thought experiment. Suppose that the economy is initially at point 1: capital flows are zero, and the real exchange rate is such that it is not worth 
moving resources either in or out of traded goods production. Now begin increasing the capital inflow. At first the economy will simply move down the V-schedule, as indicated by movement from 1 to 2 . In other words, a small capital inflow will lead to a real appreciation (a fall in e) but not to a shift of resources out of the tradeable sector. If the inflow is large enough to push the economy past point 2, however, resources will move out of the tradeable sector; this "deindustrialization" will prevent any further real appreciation. Specifically, the real exchange rate cannot appreciate beyond the point where $\mathrm{e}-1$ - rr or depreciate beyond the point where $\mathrm{e}=1+\mathrm{r}$.

What a large capital inflow will do, then, is promote a decrease in $R_{T}$, shifting the economy to a new $V$-schedule that lies to the right -. moving, say, from 2 to 3 .

Now suppose that the capital inflow were once again to decline. Then the economy would not retrace its steps. Instead it would move back along the new $V$-schedule. A return to current account balance would involve returning, not to point 1 , but to a point like point 4 . At 4 the resources in the tradeable sector are smaller than they were at 1 , and thus the real exchange rate is lower.

This special case helps illustrate how resource reallocation both responds to and itself affects the path of the real exchange rate. However, it omits by assumption any possible effect of expectations, arising either from an expected decline in temporary capital inflows or from uncertainty about future flows. As we will see, it is not possible to derive a closed form solution for the 
general case where both factors are operating. However, useful insights can be gained by considering the two effects separately.

In examining these separate cases it will be easiest if we focus on one particular value of $R_{T}$ : namely, that value for which $e=1$ when $B=0$, that is, where in the absence of capital flows the two sectors offer equal returns. The principles involved are illustrated most easily in this case, and when we want to go beyond special cases we will have to adopt numerical methods in any case, which will allow us to handle any level of $R_{T}$.

Regressive expectations

For our next special case we allow $\rho>0$, while continuing to assume $\sigma^{2}=0$. That is, any capital account imbalance is now regarded as temporary, but the future is regarded as free from uncertainty. In this case the general relation ( $\left.8^{\prime}\right)$ takes the form

$$
V\left(R_{T}, B\right)=r^{-1}\left[\alpha-\beta\left(R_{T}+B\right)\right]-r^{-1} \rho B V_{B}\left(R_{T}, B\right)
$$

or, given our choice of $R_{T}$,

$$
V\left(R_{T}, B\right)=-r^{-1} \beta B-r^{-1} \rho B V_{B}\left(R_{T}, B\right)
$$

To solve this, we make a guess at the form of the function $V($.$) : suppose that (for this particular value of R_{T}$ ) it takes the form $-A B$. Then we have 


$$
-A B=-r^{-1} \beta B+r^{-1} \rho A B
$$

implying $A=\beta(r+p)^{-1}$. So the value function is

$$
V\left(R_{T}, B\right)=-\beta B /(r+\rho)
$$

To see the implications of this, consider Figure 2. The lighter line indicates the value function corresponding to the static expectations case; this function, as we already noted, intersects the upper and lower bounds at capital flows corresponding to real exchange rates of $1+r \gamma$ and $1-r \gamma$ respectively. The heavy line indicates the value function with $\rho>0$. Since $R_{T}$ is assumed the same in both cases, the real exchange rate corresponding to any given capital flow is the same. However, the new V-schedule lies inside the band for a wider range of capital flows than the old. Thus the real exchange rate can vary more. The reason is that the movement of resources in or out of the tradeable sector, which is what limits real exchange rate variation, is inhibited by the knowledge that capital flows are only temporary. The maximum capital inflow before resources move in is $\gamma(r+\rho) / \beta$, corresponding to a real exchange rate of $1-(r+\rho) \gamma$; similarly, the maximum real exchange rate is $1+(r+\rho) \gamma$.

\section{Uncertainty}

Our remaining special case is where $\rho-0 \ldots$ that is, the capital account follows a random walk. This case doesn't make much 
economic sense, but once again it can be used to isolate a particular effect. The lesson from this case is that uncertainty about capital flows per se acts to inhibit resource reallocation.

Now one might be inclined to think that when capital flows are perceived as being equally likely to rise or fall from any starting point there would be no expected change in the real exchange rate or in the relative value of resources in the tradeable and nontradeble sectors. This is, however, not the case. The basic intuition is as follows. Suppose that at the current level of capital inflow $V$ is close to $-\gamma$ - that is, it is almost worth shifting resources out of the traded goods sector. Then if $B$ rises substantially, everyone knows that resources will be reallocated, preventing $V$ from falling below $-\gamma$. On the other hand, if $B$ falls, there is no comparable response on the other side. Thus when $V$ is close to $-\gamma$ the expected rate of change in $V$ is positive, even if $B$ follows a random walk. Similarly, when $V$ is close to $+\gamma$, its expected rate of change will be negative.

These biases in the expected change in relative valuation will have the effect of flattening out the relationship between $B$ and V, "dragging" $V$ below the static expectations locus when $B$ is low, above it when $B$ is high. The general shape is illustrated in Figure 3: a backwards $S$ that lies below the line $V=-\beta B / r$ in the upper part of the band between $\gamma$ and $-\gamma$, above it in the lower part.

Given the particular functional forms assumed in this model, it is in fact possible to derive a closed-form solution for the curve in Figure 3. Again focussing on the particular value of $R_{T}$ 
where $e=1$ when $B=0$, we can write the value function as

$$
V\left(R_{T}, B\right)=-\beta B / r+\left(\sigma^{2} / 2 r\right) V_{B B}\left(R_{T}, B\right)
$$

A functional form that works in this $c a e^{2}$ is

$$
V\left(R_{T}, B\right)=-\beta B / r+\mu\left[e^{\lambda B}-e^{-\lambda B}\right]
$$

where both $\lambda$ and $\mu$ need to be determined.

To determine $\lambda$ we note that

$$
V_{B B}\left(R_{T}, B\right)=\mu \lambda^{2}\left[e^{\lambda B}-e^{-\lambda B}\right]
$$

When we substitute this back into (12), we get

$$
-\beta B / r+\mu\left[e^{\lambda B}-e^{-\lambda B}\right]--\beta B / r+\left(\mu \sigma^{2} \lambda^{2} / 2 r\right)\left[e^{\lambda B}-e^{-\lambda B}\right]
$$

But this must be true for all values of $B$, which can only be true if

$$
\lambda=\left(2 r / \sigma^{2}\right)^{1 / 2}
$$

To determine $\mu$ we first note that in order to get the general shape illustrated in Figure 3, we must have $\mu<0$. The specific ${ }^{2}$ This function is chosen to be symmetric around $B=0$, as we would expect for the particular value of $R_{T}$ chosen. More generally, the form is $\left[\alpha-\beta\left(R_{T}+B\right)-1\right] / r+\mu_{1} e^{\lambda B}+\mu_{2} e^{-\lambda B}$. 
value of $\mu$ is determined by the requirement that the curve be precisely tangent to the edges of the band, $i . e .$, reach a maximum at $\gamma$ and a minimum at $-\gamma$. This is the "smooth pasting" condition of option-pricing theory, which has recently been shown to play a role in a wide variety of problems of behavior under uncertainty (see Krugman 1987 for an application to target zone exchange rate regimes, Dixit 1987 a for an application to entry and exit under fluctuating exchange rates, and Dumas 1988 for an application to international investment). The parallel with option pricing should not be surprising: agents, in valuing resources in this model, know that they have the future option of moving the resources to the other sector; their decision to do so is therefore like exercising an option, and the optimal allocation problem has associated with it a value function that looks a lot like an option pricing problem.

The important point in terms of the economics is that the effect of uncertainty in this case is to inhibit resource movements and thus widen the range of possible real exchange rate variation. This may be seen clearly from Figure 3, where the $V$-function is flatter than the static-expectations locus and thus intersects the edges of the band at higher and lower values of $B$ than in the static-expectations case; the result will therefore be that the real exchange rate can move to levels that would have been impossible, ruled out by the possibility of deindustrialization or reindustrialization, if there were no uncertainty. That is, uncertainty generates a "wait-and-see" attitude that discourages movement of resources between sectors. 
An alternative way to think about this is to push the option analogy: moving resources is like exercising an option. In the face of volatility, options will not be exercised as soon as they are in the money, that is, as soon as the market price exceeds the contract price. Instead, it is optimal to hold out for a higher price, with the optimal exercise price increasing in volatility. Similarly, uncertainty makes agents reluctant to move resources, with their reluctance an increasing function of volatility.

We have now shown two reasons why an unstable pattern of capital flows may lead to wider real exchange rate fluctuations than would be produced by persistent, predictable capital flows of the same magnitude. To the extent that capital flows are perceived as temporary, firms are reluctant to reallocate resources; even if the capital flows do not show a tendency to revert to the mean, the "option" cost of reallocating resources inhibits deindustrialization and reindustrialization. Our next step is to combine these two motives and examine the behavior of the general model .

4. The general case and real exchange rate dynamics

The general equation for the value function given the behavior of B described by (6) is

$$
\mathrm{V}\left(\mathrm{R}_{\mathrm{T}}, \mathrm{B}\right)=\left[\alpha-\beta\left(\mathrm{R}_{\mathrm{T}}+\mathrm{B}\right)-1\right] / \mathrm{r}-(\rho / \mathrm{r}) \mathrm{V}_{\mathrm{B}}\left(\mathrm{R}_{\mathrm{T}}, \mathrm{B}\right)+\left(\sigma^{2} / 2 \mathrm{r}\right) \mathrm{V}_{\mathrm{BB}}\left(\mathrm{R}_{\mathrm{T}}, \mathrm{B}\right)
$$

This has no closed-form solution, but it can be solved 
numerically. The general shape will be the same as that illustrated in Figure 3; that is, for each value of $R_{T}$ there will be a backwards-S that is tangent to the edges of the band defined by the maximum and minimum values of $V$. We can denote the maximum and minimum values of $B$ for any given $R_{T}$ as $B_{\max }\left(R_{T}\right)$ and $B_{\min }\left(R_{T}\right)$. The numerical solution procedure is a "shooting" technique". We make a guess at $B_{\min }\left(R_{T}\right)$. We know that at that point $V=y$ and $V_{B}=0$, which allows us to infer $V_{B B}$ from (17). Once we have estimated $V_{B}$ and $V_{B B}$ at one point, we can then compute $V$ and $V_{B}$ for a slightly higher value of $B$, find the value of $V_{B B}$ necessary to justify this $V$, and repeat. This allows computation of the value function passing through our initial guess. We then search over starting values of $B_{\min }\left(R_{T}\right)$ until we find one for which the minimum value of $\mathrm{V}$ is - $\gamma$-. that is, where the function is tangent to the bottom as well as the top of the band.

Figure 4 shows the value function computed for the parameters shown in Table 1 , as well as the static expectations locus. The value of $R_{T}$ chosen is that for which $e=1$ when $B-0$, that is, resources earn the same return in the two sectors when trade is balanced. The values of $\gamma$ and $r$ imply that in a static expectations world the maximum and minimum values of $e$ would be 1.05 and -0.95 , that is, a five percent shift in the exchange rate would be enough to induce resources to move. However, $\rho=0.2 \ldots$ capital flows are viewed as transitory, with a mean persistence of five years; and substantial volatility is also introduced.

${ }^{3}$ This technique was suggested by the analysis of target zones in Miller and Weller (1988). 
The consequence of the combination of expected mean-reversion and uncertainty is a drastic widening of the range of potential real exchange rate variation. The "range of no change", the range of capital flows for which resources will not be reallocated, is almost 5 times as large as in the static expectations case. Thus the range of potential real exchange rate variation is also five times as large, that is, plus or minus 24.8 percent.

We can also now consider the general dynamics of the real exchange rate. The V-schedule in Figure 4 is one of a family of such curves, each corresponding to a different value of $R_{T}$, as illustrated in Figure 5. As B fluctuates, it moves the economy up or down a particular curve until $\mathrm{V}$ hits $\gamma$ or $-\boldsymbol{\gamma}$. Then the economy shifts resources into or out of the traded goods sector, so that we move along the edge of the band. Then when $B$ reverses direction the economy moves back along the backwards-S that is tangent to the band at the highest or lowest $B$ reached.

A typical exchange rate cycle might involve the path illustrated as 1234 in the figure. Starting from an equilibrium in the middle of the band, rising capital inflows would at first lead to real appreciation but not to resource reallocation. When point 2 is passed, however, the economy will begin to shift resources out of tradeables; the real exchange rate at which this takes place is considerably below that at which such a shift would have taken place if the capital flows were regarded as permanent. The further rise in $B$ to point 3 produces no further real appreciation, only more reallocation. If $B$ now begins to fall, the economy moves back along the $\mathrm{V}$-schedule that is tangent to the 
band at 3, and thus returns to 4, not to 1 ; since $R_{T}$ is lower at the end of this cycle than at the beginning, the real exchange rate is higher. Looking at the path of $e$ over time, we get the results illustrated in Figure 6 . The broken lines show the maximum and minimum values of $e$ in a static expectations world; the figure shows both that the range of real exchange variation is wider in an uncertain world and that a large exchange rate movement that leads to deindustrialization must be offset by a subsequent overshooting in the opposite direction.

\section{Implications}

This paper has offered a simple model that appears to confirm recent intuitions about real exchange rate behavior. Perceptions that capital flows are temporary and/or uncertain discourage reallocation of resources even when the real exchange rate produces large differences in returns between tradeable and nontradeable sectors, and this reluctance to shift resources in turn widens the fluctuations of the real exchange rate.

An interesting corollary of the analysis is that economic policy can shift the trade balance by influencing beliefs about the process generating capital flows as well as by changing the current real exchange rate. Currently officials at the IMF and other organizations concerned about the US trade deficit argue that the US trade deficit will fall if only firms can be convinced that in future the dollar will remain stable at its current level - that is, if their caution over the possibility of a rebound can 
be cured. This is the kind of idea that makes sense in this model. of course, the IMF would then follow this with the assertion that stable macroeconomic policies plus targets for nominal exchange rates can in fact alter the process generating capital flows in a desirable way. This assertion cannot be tested in this model, since capital flows were treated as exogenous. This points to the clear next step in this modelling effort, the integration of real models like this one with the monetary factors that most economists believe underlie exchange rate fluctuations in practice.

Thus this paper is not the last word on its subject, by a long shot. However, I hope that it does make convincingly the case that to understand exchange rate dynamics we must also address the dynamics of resource reallocation.

\section{REFERENCES}

Baldwin, R. and P. Krugman (1986): "Persistent trade effects of large exchange rate shocks", NBER Working Paper.

Dixit, A. (1987a): "Entry and exit decisions of firms under fluctuating exchange rates"; mimeo, Princeton University.

Dixit, A. (1987b): "Hysteresis, import penetration, and exchange rate pass-through", mimeo, Princeton University

Dumas, B. (1988): "Pricing physical assets internationally", mimeo, Wharton. 
Krugman, P. (1987): "Trigger strategies and price dynamics in equity and foreign exchange markets", NBER Working Paper \#2459.

Krugman, P. (1988): Exchange Rate Instability, The Robbins Memorial Lectures, MIT Press, forthcoming.

Miller, M. and P. Weller (1988): "Target zones, currency options, and the dollar", mimeo, University of Warwick. 
Table 1: Parameter values for Figure 4

$$
\begin{array}{lll}
\alpha=2 & \rho=0.2 & \mathrm{R}_{\mathrm{T}}=1 \\
\beta=1 & \sigma^{2}=0.01 & \\
\gamma=0.5 & \mathrm{r}=0.1 &
\end{array}
$$




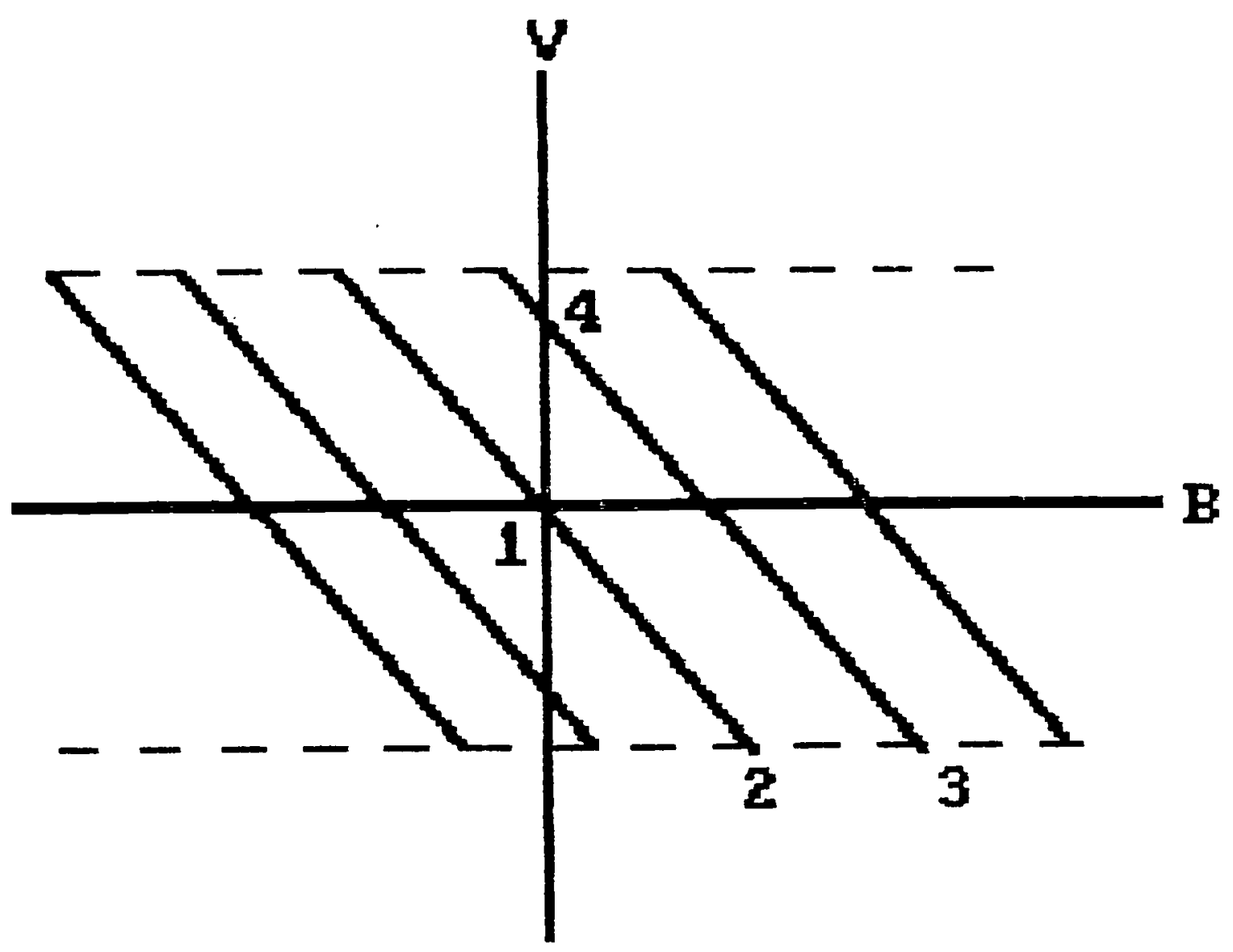

Figure 1 


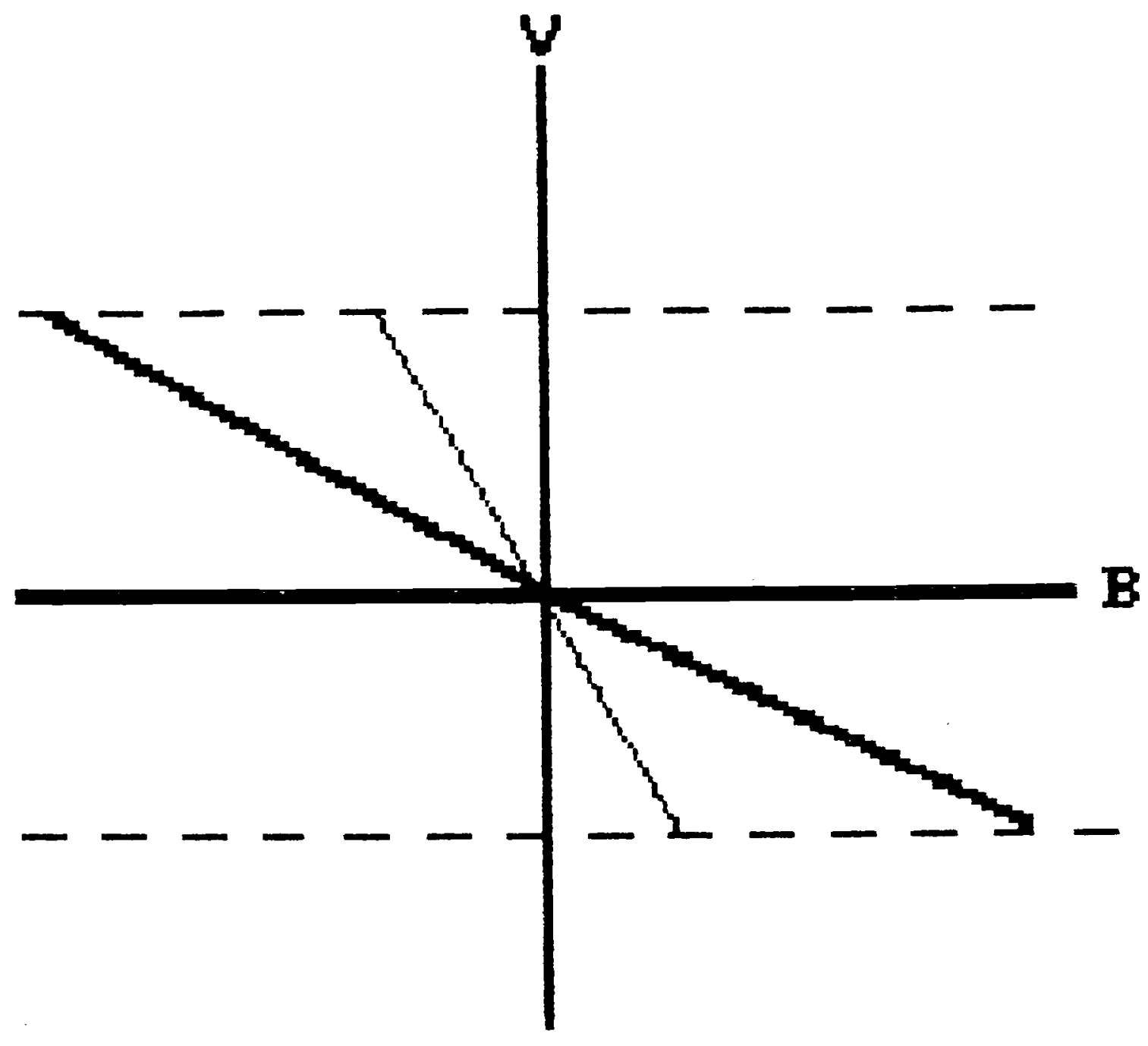

Figure 2 


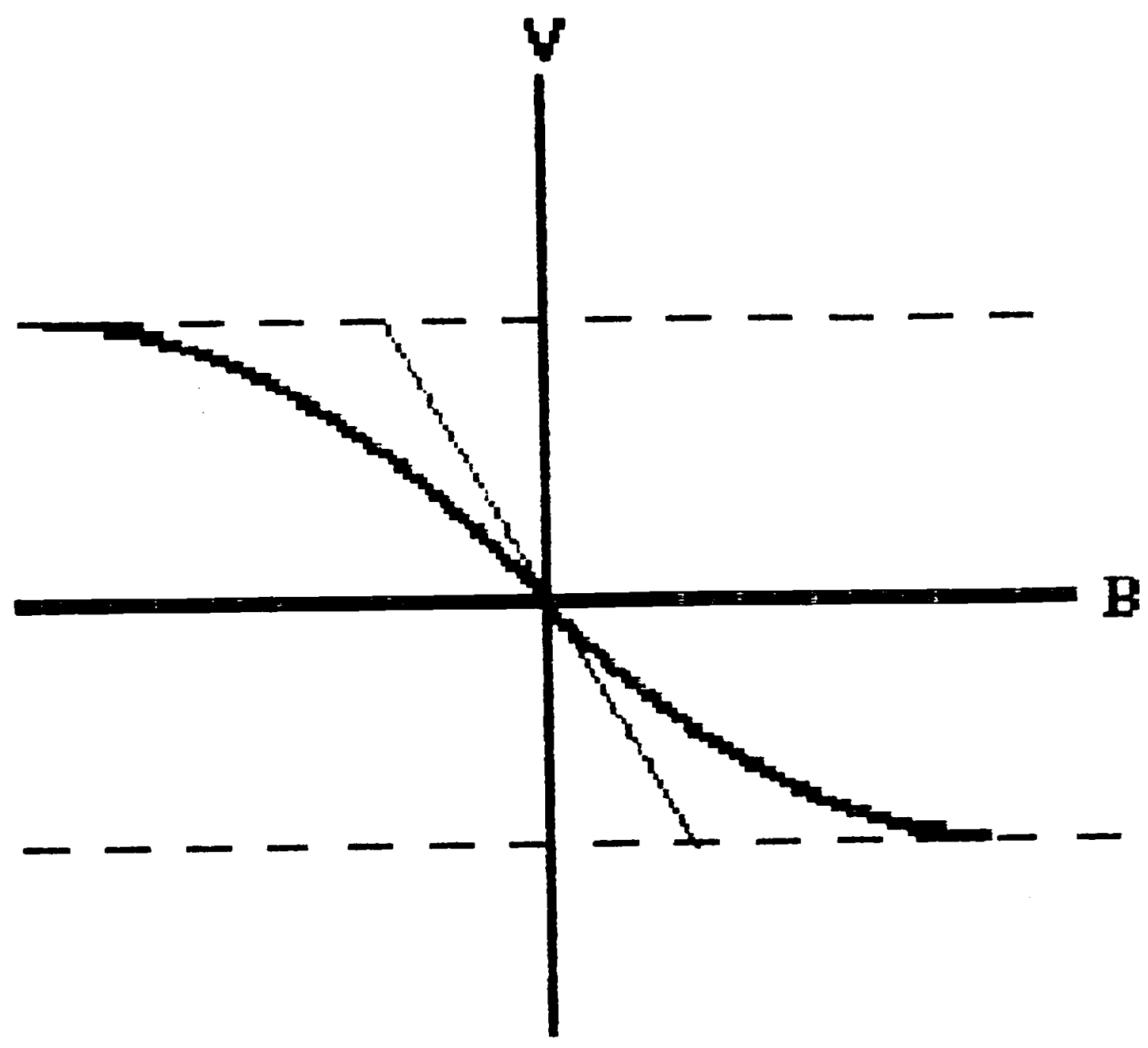

Figure 3 


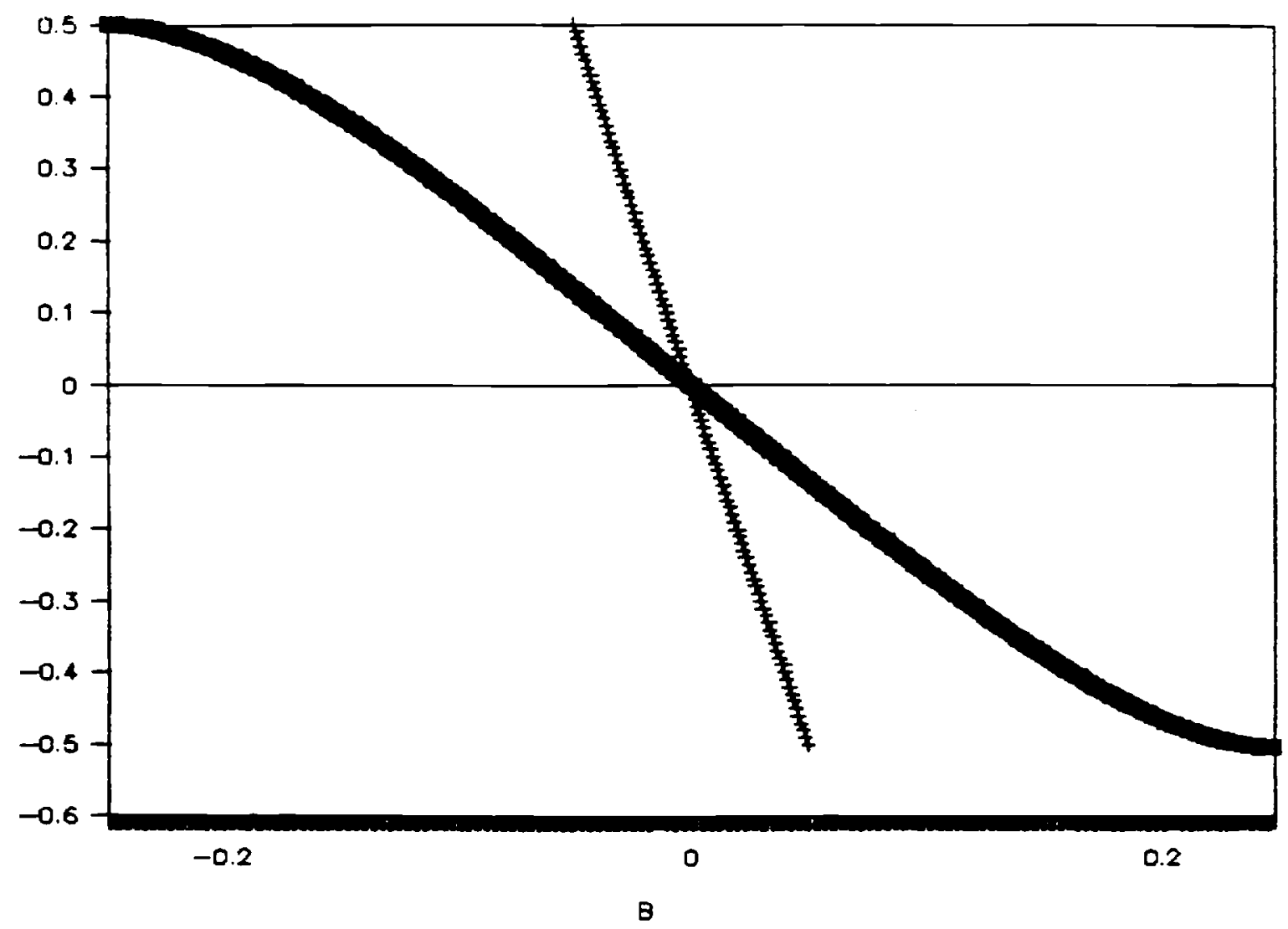

Figure 4 


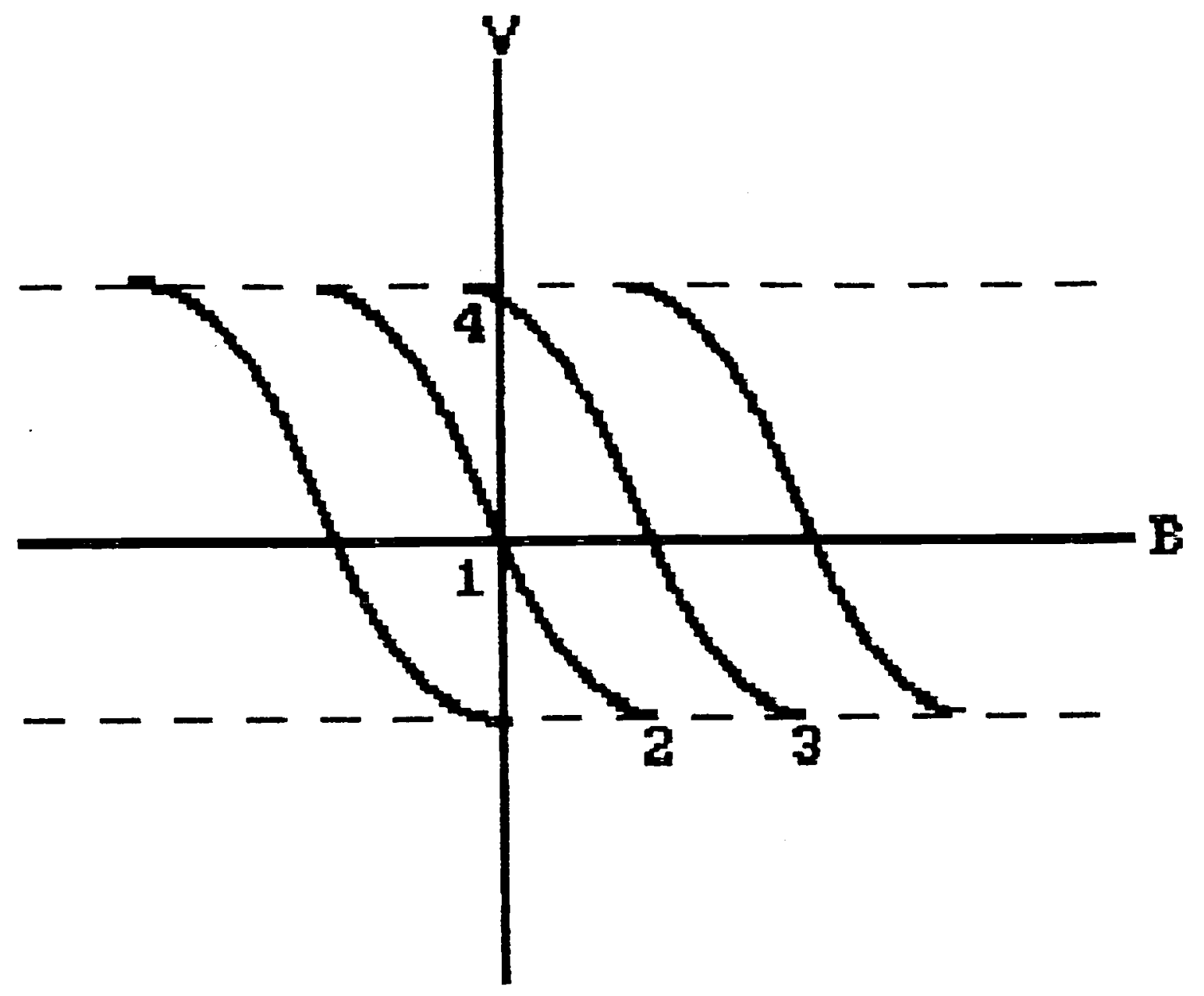

Figure 5 


$$
\mathcal{L}
$$

